Article

\title{
Effect of Thermal Modification on the Nano-Mechanical Properties of the Wood Cell Wall and Waterborne Polyacrylic Coating
}

\author{
Yan $\mathrm{Wu}^{1,2}$, Xinyu $\mathrm{Wu}^{1,2}$, Feng Yang ${ }^{3, *}$, Haiqiao Zhang ${ }^{1,2}$, Xinhao Feng ${ }^{1,2}$ and Jilei Zhang ${ }^{4}$ \\ 1 College of Furnishings and Industrial Design, Nanjing Forestry University, Nanjing 210037, China; \\ wuyan@njfu.edu.cn (Y.W.); wuxinyu@njfu.edu.cn (X.W.); zhanghaiqiao@njfu.edu.cn (H.Z.); \\ fengxinhao@njfu.edu.cn (X.F.) \\ 2 Co-Innovation Center of Efficient Processing and Utilization of Forest Resources, \\ Nanjing Forestry University, Nanjing 210037, China \\ 3 Beijing Institute of Fashion Technology, Fashion Accessory Art and Engineering College, \\ Beijing 100029, China \\ 4 Department of Sustainable Bioproducts, Mississippi State University, Starkville, MS 39762, USA; \\ jz27@msstate.edu \\ * Correspondence: yangfeng@bift.edu.cn
}

Received: 20 October 2020; Accepted: 17 November 2020; Published: 25 November 2020

\begin{abstract}
Masson pine (Pinus massoniana Lamb.) samples were heat-treated at different treatment temperatures $\left(150,170\right.$, and $\left.190{ }^{\circ} \mathrm{C}\right)$, and the nano-mechanical properties of the wood cell wall, which was coated with a waterborne polyacrylic (WPA) lacquer product, were compared. The elastic modulus $\left(E_{\mathrm{r}}\right)$ and hardness $(H)$ of wood cell wall and the coating were measured and characterized by nanoindentation, and the influencing factors of mechanical properties during thermal modification were investigated by chemical composition analysis, contact angle analysis, and colorimetric analysis. The results showed that with the increase in the heat treatment temperature, the contact angle of the water on the wood's surface and the colorimetric difference increased, while the content of the cellulose and hemicelluloses decreased. After thermal modification of $190{ }^{\circ} \mathrm{C}$, the $E_{\mathrm{r}}$ and $H$ of the wood cell wall increased by $13.9 \%$ and $17.6 \%$, respectively, and the $E_{\mathrm{r}}$ and $H$ of the WPA coating applied to the wood decreased by $12.1 \%$ and $22.2 \%$. The $E_{\mathrm{r}}$ and $H$ of the interface between the coating and wood were lower than those near the coating's surface. The $E_{\mathrm{r}}$ and $H$ of the cell wall at the interface between the coating and wood were lower than those far away from the coating. This study was of great significance for understanding the binding mechanism between coating and wood cell walls and improving the finishing technology of the wood materials after thermal modification.
\end{abstract}

Keywords: Masson pine; nanoindentation; thermal modification; coating; nano-mechanical properties

\section{Introduction}

Due to the fact of long-term exposure to external influences, such as water, heat, ultraviolet radiation, or mechanical stress, the properties of wood degrade easily $[1,2]$. There is no doubt that improving the mechanical properties and reducing the moisture absorption of wood is of great significance for improving the utilization rate of wood [3-7]. The reduction of water adsorption is the key factor to improving the durability of wood products [8]. Cellulose and hemicelluloses contain large amounts of hydroxyl, which makes wood hydrophilic [9]. Therefore, the extraction of cellulose and hemicelluloses can improve the properties of water-resistance wood $[9,10]$. Thermal modification refers to the heat treatment of wood in steam, air, inert gas, water, or oil, that is, through thermal decomposition of the internal physical and chemical compositions, the growth stress and drying stress of wood can 
be removed $[9,11,12]$. In the process of modification, acetic acid is released due to the hydrolysis of hemicellulose. Because crystalline cellulose is more stable, the acetic acid can induce the polymerization of cellulose, which improves the crystallinity of cellulose [13,14]. Stanzl-Tschegg et al. [15] used nanoindentation to investigate the properties of hardness in the longitudinal direction of beech wood with thermal modification. Wang et al. [16] evaluated the effects of thermal modification on the physical, chemical, and micromechanical properties of Masson pine wood. The results showed that the relative content of lignin and crystallinity increased with the increase of the temperature and time of heat treatment, and the hardness $(H)$ and elastic modulus $\left(E_{\mathrm{r}}\right)$ increased with the increase of the creep ratio decrement of cell walls (CWs).

There are two methods for improving the mechanical properties of wood, namely, increasing the density of wood or filling the lumen of wood cells [17]. The coating, which can fill the lumen of wood cells, plays an important role in endowing wood with function and isolating it from the outside world [1,18-20]. So, it is widely applied to protect the wood and extend its service life. Nanoindentation is a very powerful tool to study the correlation between microstructure and mechanics [21,22]. Jiang et al. [23] once used nanoindentation to investigate the mechanical properties of the paint films of wood flooring. The advantage is that the mechanical properties of materials that are closer to the nanoscale can be measured directly $[24,25]$. The effects of multilayer waterborne polyacrylic coatings on the mechanical properties of the cell walls of southern pine were studied by nanoindentation in a previous study of our research group [26]. It was found that the mechanical properties of the cell walls decreased because the dispersant of the coating penetrated the cell wall. The $E_{\mathrm{r}}$ and $H$ of the coating increased with the decrease in the distance between the indentation point and the wood surface. Intact cell walls adjacent to or far from the coating represented higher $E_{\mathrm{r}}$ and $H$.

Masson pine (Pinus massoniana Lamb.) is the main timber tree in the south of China and has a high economic value. Due to the fact of its poor dimensional stability and durability, heat treatment or finishing treatment for Masson pine can improve some of its properties and enlarge its application in papermaking, rubber, coating, paint, adhesives, and other industries [26]. Hamiyet Sahin [27] heat-treated pine (Pinus nigra Arnold.) and fir (Abies bornmülleriana Mattf.) and found a decrease in the modulus of rupture, modulus of elasticity in bending, and impact bending strength. Gurleyen et al. [28] and Ayata et al. [29] studied the effect of thermal modification on oak wood with different coatings, and the results showed that the lightness, adhesion strength, and hardness decreased with the intensity of the treatment. It showed that heat treatment affected the binding mechanism of the wood's surface and coating. To better understand this degradation of the properties of the wood or the coating after heat treatment, in this experiment, wood samples of Masson pine (Pinus massoniana Lamb.) were modified at different temperatures and then coated with a waterborne polyacrylic lacquer product (WPA) to compare the effects of temperature on the mechanical properties of CWs and the coating layer. Heat treatment is a technologically advanced process involving three variables: heat, pressure, and water [30]. The degree of thermal degradation of wood depends largely on temperature and exposure time $[2,11,31,32]$. Too high of a heat treatment temperature will lead to the decline in the mechanical properties of the wood [14,33]. The reduction in mechanical properties greatly affects the application range of thermal modification. Therefore, a moderate range from 150 to $190{ }^{\circ} \mathrm{C}$ was selected for the heat treatment of the wood. A chemical composition analysis, contact angle test, chromaticity analysis, and nanoindentation test were used to explore how thermal modification affects the chemical and mechanical properties of CWs and the binding mechanism between the coating and CWs.

\section{Materials and Methods}

\subsection{Materials}

The Masson pine (Pinus massoniana Lamb.) cut around the same latewood growth ring from the sapwood was from Fujian, China. The wood samples with a moisture content (MC) of $\approx 12 \%$ were 
$20 \mathrm{~mm}$ in length, width, and height, and they were kept at $65 \pm 3 \%$ relative humidity (RH) at $20 \pm 2{ }^{\circ} \mathrm{C}$. The waterborne polyacrylic (WPA) lacquer product which contained alkyl propanols, ethylene glycol ethers, and 1-methyl-2-pyrrolidinone was purchased from the Upper Saddle River, NJ, USA. The solids content, $\mathrm{pH}$ value, and the viscosity at $25^{\circ} \mathrm{C}$ of the coating were $30 \%, 6$ and $570 \mathrm{MPa} \cdot \mathrm{s}$, respectively.

\subsection{Thermal Modification}

The Masson pine wood samples were oven-dried at $80^{\circ} \mathrm{C}$ to gain weight constancy. Then the dried samples were divided into four treatment groups including a group without thermal modification and three groups of different treatment temperatures. The three groups were treated under atmospheric pressure in an oven (Thermo Scientific, Asheville, NC, USA) with $\mathrm{N}_{2}$-flow of $20 \mathrm{~mL} \cdot \mathrm{min}^{-1}$ at 150, 170, and $190^{\circ} \mathrm{C}$ for $2 \mathrm{~h}$ [32]. The wood samples after thermal modification were then cooled down to room temperature inside the conditioning chamber and sustained at $20{ }^{\circ} \mathrm{C}$ and $65 \% \mathrm{RH}$.

\subsection{Coating Process}

The surface of the samples were first smoothed by employing a microtome and then coated along the grain direction. Then, the samples were air-dried for two hours. The surface of the samples were sanded with 220 grit sandpaper for the preparation of the second application. The construction method of the second and third layers was the same as the finishing method of the first layer. Finally, all coated samples were stored in a sterile environment where the relative temperature was $20{ }^{\circ} \mathrm{C}$ and the humidity was $30 \%$. By comparing the thickness of the coating sample with that of the original wood, the coating thickness was calculated as $80 \mu \mathrm{m}$. The preparation of TMWs was shown in Figure 1.
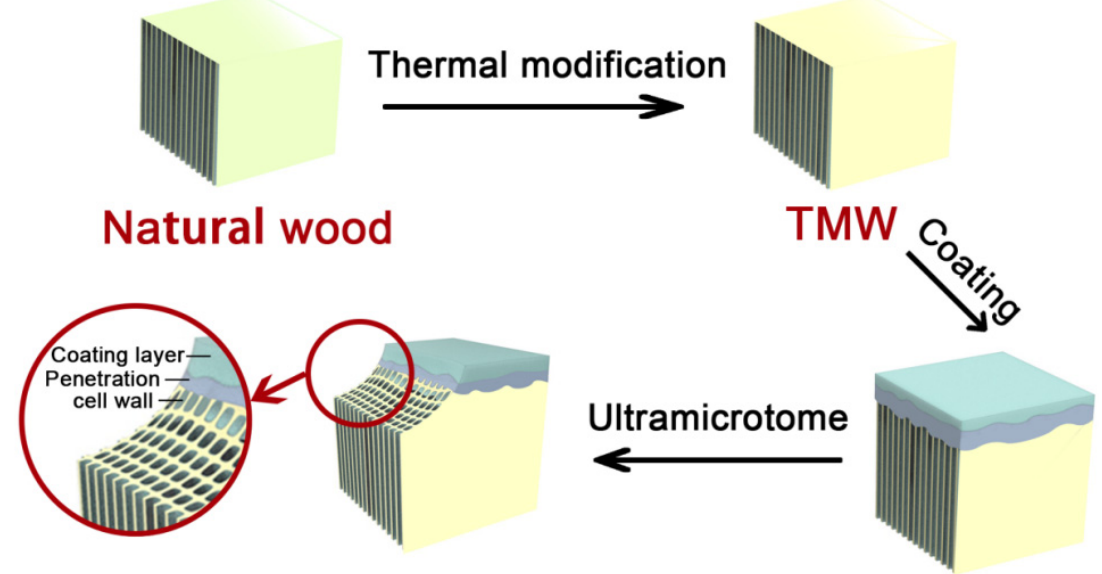

Figure 1. Schematic diagram of the preparation of the sample. Thermally modified woods (TMWs).

\subsection{Chemical Composition}

The powders for the control and thermally modified woods (TMWs) were prepared for analysis. The National Renewable Energy Laboratory (NREL) method was used to compare the corresponding sample characteristics under different treatment temperatures. The main components of the wood were analyzed qualitatively and quantitatively through via testing for three elements (i.e., lignin, cellulose, and hemicellulose). The chemical reagents used above were supplied by Jiuyi chemicals, Shanghai, China.

\subsection{Contact Angle Test}

The contact angle of water on the longitudinal direction of the four sample groups was measured by a Theta $\mathbf{2} 200$ Optical contact goniometer (Sweden Biotin Technology Co. Ltd., Gothenburg, Sweden). After being dried at $40{ }^{\circ} \mathrm{C}$ for $2 \mathrm{~h}$, the samples, which were stored at a room temperature of $20^{\circ} \mathrm{C}$, 
were placed on the loading platform. Approximately $2 \mu \mathrm{L}$ of deionized water was dripped onto the surface of the samples under test. The sample was tested three times in parallel at different locations.

\subsection{Colorimetric Analysis}

The chromaticity was conducted by RM200-PT01 Imaging colorimeter (Xintaike Instruments, Beijing, China). The Standard D65 light was used and the angle of the light was $0^{\circ}$. According to the colorimetric system of $\mathrm{L}^{*} \mathrm{a}^{*} \mathrm{~b}^{*}$, the surfaces of the samples were tested at different locations ten times, and the average value was calculated. The instrument's chromaticity was calibrated before each test. The samples after thermal modification were kept at room temperature and the relative humidity was $65 \%$. The values of the color difference test for the samples are respectively expressed by three parameters $\mathrm{L}^{*}, \mathrm{a}^{*}$, and $\mathrm{b}^{*}$. Chroma value and chroma difference value are calculated according to the following formula:

$$
\begin{gathered}
\Delta \mathrm{a}_{\mathrm{t}}{ }^{*}=\mathrm{a}_{\mathrm{t}}{ }^{*}-\mathrm{a}_{0}{ }^{*} \\
\Delta \mathrm{b}_{\mathrm{t}}{ }^{*}=\mathrm{b}_{\mathrm{t}}{ }^{*}-\mathrm{b}_{0}{ }^{*} \\
\Delta \mathrm{E}^{*}=\sqrt{\left(\Delta \mathrm{L}_{\mathrm{t}}^{*}\right)^{2}+\left(\Delta \mathrm{a}_{\mathrm{t}}\right)^{2}+\left(\Delta \mathrm{b}_{\mathrm{t}}{ }^{*}\right)^{2}}
\end{gathered}
$$

where $\mathrm{L}_{0}{ }^{*}, \mathrm{a}_{0}{ }^{*}, \mathrm{~b}_{0}{ }^{*}$ represent the chromaticity values of the original samples, and $\mathrm{L}_{\mathrm{t}}{ }^{*}, \mathrm{a}_{\mathrm{t}}{ }^{*}, \mathrm{~b}_{\mathrm{t}}{ }^{*}$ represent the chromaticity values of the samples after heat treatment, respectively.

\subsection{Nanoindentation (NI)}

Before nanoindentation, all samples were stored in a sterile environment where the temperature and relative humidities were $20{ }^{\circ} \mathrm{C}$ and $50 \pm 3 \%$. To reduce the average roughness of the coated wood samples, the samples with a size of $5 \mathrm{~mm}$ (long) $\times 5 \mathrm{~mm}$ (wide) $\times 10 \mathrm{~mm}$ (thick) were polished with a diamond knife (Micro Star Inc., TX, USA) combined with ultramicrotomy (Leica Microsystems Inc., Buffalo Grove, IL, USA). According to the methods of Wang [32], nanoindentation was carried out on a Hysitron TriboIndenter system (Hysitron Inc., Minneapolis, MN, USA) with a scanning probe microscopy (SPM) and a Berkovich indenter. The $E_{\mathrm{r}}$ and $H$ of the CWs of the samples of the same growth ring were measured. The $E_{\mathrm{r}}$ and $H$ of the coating were measured on the coating that was applied to the TMW. With load application for $5 \mathrm{~s}$, holding time for $5 \mathrm{~s}$, and unload time for $5 \mathrm{~s}$, the S2 layer was indented under the open-loop mode of the three-stage load ramp, and the peak load was $400 \mu \mathrm{N}$. As can be seen in Figure 2, the SPM images were attached to ensure the quality of indents. As shown in Figure 2A, to ensure the reliability of the experiment, six to ten indents were analyzed for the coating or CWs of each sample, which were all located in valid areas [34]. Figure 2A shows the indents on the coating layer. As shown in Figure 2B, the CWs of type I refer to the broken cell wall at the coating layer, and the coating of type I refers to the coating penetrated in the cell wall of type I. As shown in Figure 2C, the cell wall of type II refers to the intact cell wall close to the coating layer. Figure 2D shows the indents on the CWs of type III, which represents the intact cell wall far away from the coating layer. The coating far away from the CWs is named C; The coating penetrated into the CWs of type I is called I-C; The CWs of type I is named I-W; The coating penetrated in the CWs of type II is named II-C; The CWs of type II is named II-W; The CWs of type III is named III-W. 

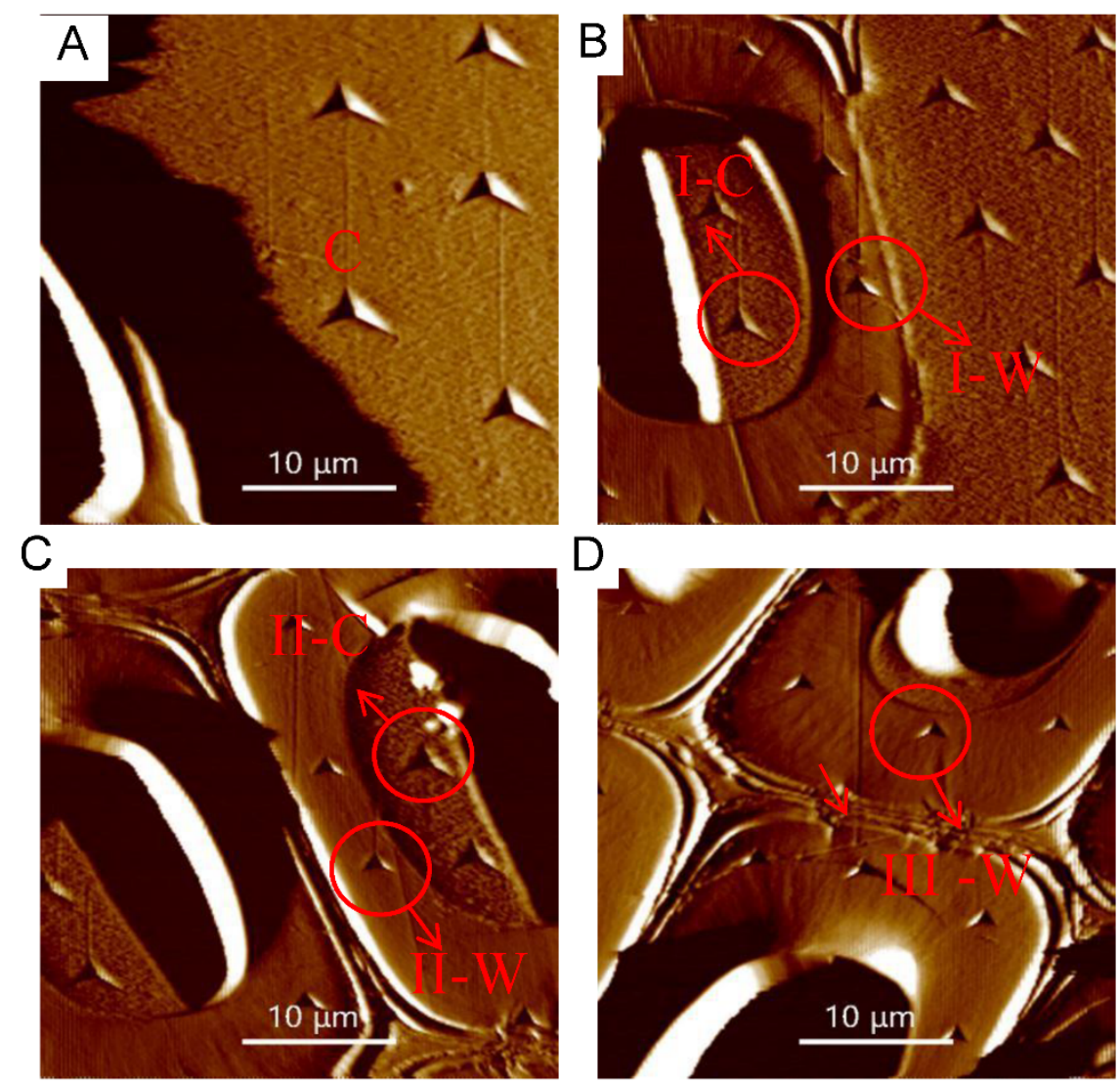

Figure 2. Scanning probe microscopy (SPM) images of test locations and the indents after characterization by nanoindentation: (A) indents on the coating layer; (B) indents on I-C and I-W; (C) indents on II-C and II-W; (D) indents on III-W.

According to the method of Oliver and Pharr (1992) [35], the $E_{\mathrm{r}}$ and $H$ were calculated as follows:

$$
\begin{gathered}
\mathrm{E}_{r}=\frac{\sqrt{\pi}}{2 \beta} \frac{S}{\sqrt{A}} \\
\mathrm{H}=\frac{\mathrm{P}_{\max }}{\mathrm{A}_{h c}}
\end{gathered}
$$

where $S$ is initial unloading stiffness, and $\beta$ is a correction factor whose value is equal to 1.034 . $P_{\max }$ refers to the peak load, $A$ refers to the projected contact area, and $\mathrm{A}_{h c}$ is the representation of the projected contact area at peak load. The H impression of the SPM images shows that the shape of the indentation was not strictly triangular, and that the edges on both sides of the indentation pit had different shapes. This was because the substrate-induced enhancement of the pileup increased the indentation contact area [35,36]. In addition, due to the structural compliance issues inherent in CWs, when the indentation is close to the interface between the wood and the coating, the edge effects will also affect the measurement of $E_{\mathrm{r}}$ and $H[37,38]$.

\section{Results and Discussion}

\subsection{Chemical Composition}

Figure 3 illustrates the changes in the main chemical components of Masson pine wood as a function of temperature. As can be seen from Figure 3, the content of cellulose increased and then decreased during the process of thermal modification. Moreover, the hemicellulose of wood decreased after thermal modification, while the content of lignin increased with the increase in the temperature 
of thermal modification. Compared with the CWs of the untreated wood, the content of cellulose and hemicellulose of TMWs decreased by $7.1 \%$ and $27.7 \%$, respectively. When the temperature of thermal modification was $190^{\circ} \mathrm{C}$, owing to the decrease in the ratio of the cellulose and hemicellulose, the content of lignin reached the highest, accounting for $29.5 \%$. This was because the thermal modification caused the degradation of cellulose and hemicellulose. The condensation reaction of lignin also took place with the increase in hemicellulose pyrolysis products (depolymerization) used for polymerization of lignin when the thermal decomposition temperature increased to $190{ }^{\circ} \mathrm{C}[13,39]$.

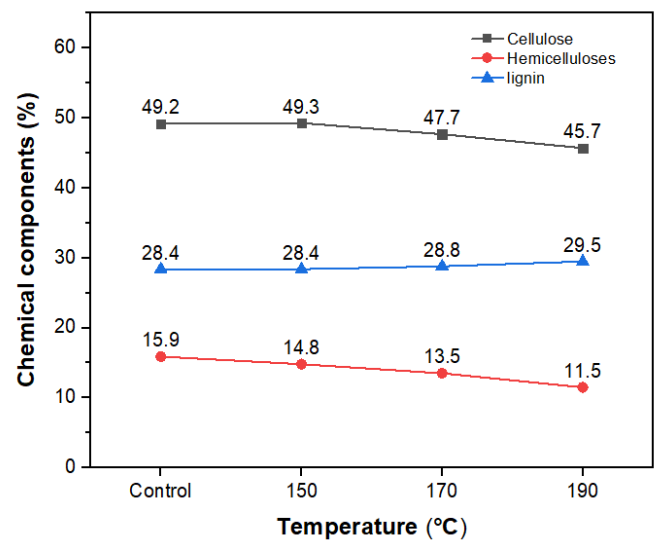

Figure 3. Main chemical components of Masson pine wood as a function of temperature.

\subsection{Contact Angle of Water (CA)}

There are a large number of hydroxyl groups in cellulose and hemicelluloses, which endow wood with hydrophilic properties [40,41]. Heat treatment can reduce the moisture absorption of wood [42]. As shown in Figure 4, the contact angle of the water (CA) on the surface of TMW was greater than that of the untreated wood. With the increase in temperature, the CA on the surface of TMW increased gradually. This was because the thermal modification led to the degradation of hemicelluloses, contributing to the decrease in the free hydrophilic hydroxyl group inside the wood, which reduced the water absorption of the wood and endowed the wood with certain hydrophobic properties [43-46].

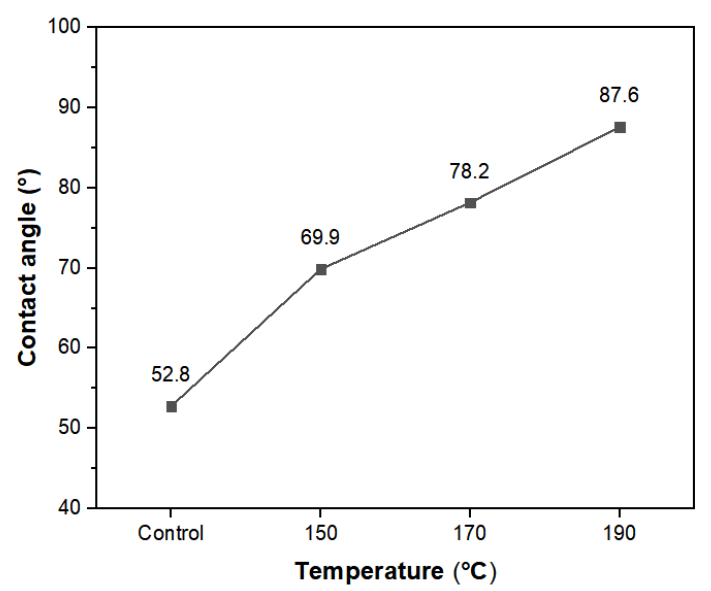

Figure 4. Contact angle analysis of Masson pine wood as a function of temperature.

\subsection{Colorimetric Analysis}

As shown in Table 1 , the value of $L^{*}, a^{*}, \Delta a^{*}$, and $\Delta E^{*}$ of wood presented an upward trend with the increase of temperature, while the value of $b^{*}$ and $\Delta b^{*}$ first rose and then fell with the increase in temperature. When the treatment temperature was $190^{\circ} \mathrm{C}$, the colorimetric difference between 
TMWs and the untreated wood was the largest, and the color of treated wood became darker and redder. This phenomenon was due to the fact that during the process of thermal modification with the evaporation of water, the extractives inside the wood migrated to the surface of the wood and occurred oxidation. At the same time, the degradation of hemicellulose led to the production of more chromophoric groups such as carboxyl groups. In addition, the relative content of lignin increased, which was accompanied by the generation of condensation reaction to produce quinone substances. These factors worked together to cause the darker tendency of the color of treated wood. Figure 5 illustrates the colorimetric difference of $a^{*}$ and $b^{*}$ of the untreated wood and TMWs. It can be seen that when the treatment temperature was $150^{\circ} \mathrm{C}$ and $190^{\circ} \mathrm{C}$, the colorimetric difference changed sharply, while when the temperature was $170^{\circ} \mathrm{C}$, the colorimetric difference changed gently. This was since the oxidation of the extractives or the degradation of hemicellulose were insignificant between $150{ }^{\circ} \mathrm{C}$ and $170{ }^{\circ} \mathrm{C}$ and did not have a significant effect on the colorimetric difference.

Table 1. Colorimetric analysis of Masson pine wood as a function of temperature. $\left(L^{*}, a^{*}, b^{*}\right.$ represent the lightness index, the red-green axis index, and the yellow-blue axis index, repectively; $\Delta L^{*}$ represents lightness difference, $\Delta a^{*}$ and $\Delta b^{*}$ represent color index difference, $\Delta E^{*}$ represents overall color difference).

\begin{tabular}{lccccccc}
\hline Temperature & $\boldsymbol{L}^{*}$ & $\boldsymbol{a}^{*}$ & $\boldsymbol{b}^{*}$ & $\boldsymbol{\Delta} \boldsymbol{L}^{*}$ & $\boldsymbol{\Delta} \boldsymbol{a}^{*}$ & $\boldsymbol{\Delta} \boldsymbol{b}^{*}$ & $\boldsymbol{\Delta} \boldsymbol{E}^{*}$ \\
\hline Control & 81.2 & 10.0 & 36.0 & - & - & - & - \\
$150^{\circ} \mathrm{C}$ & 75.6 & 13.6 & 38.4 & -5.6 & 3.6 & 2.4 & 7.1 \\
$170^{\circ} \mathrm{C}$ & 74.4 & 14.1 & 37.2 & -6.8 & 4.1 & 1.2 & 8.0 \\
$190^{\circ} \mathrm{C}$ & 66.6 & 15.1 & 33.0 & -14.6 & 5.1 & -3 & 15.7 \\
\hline
\end{tabular}

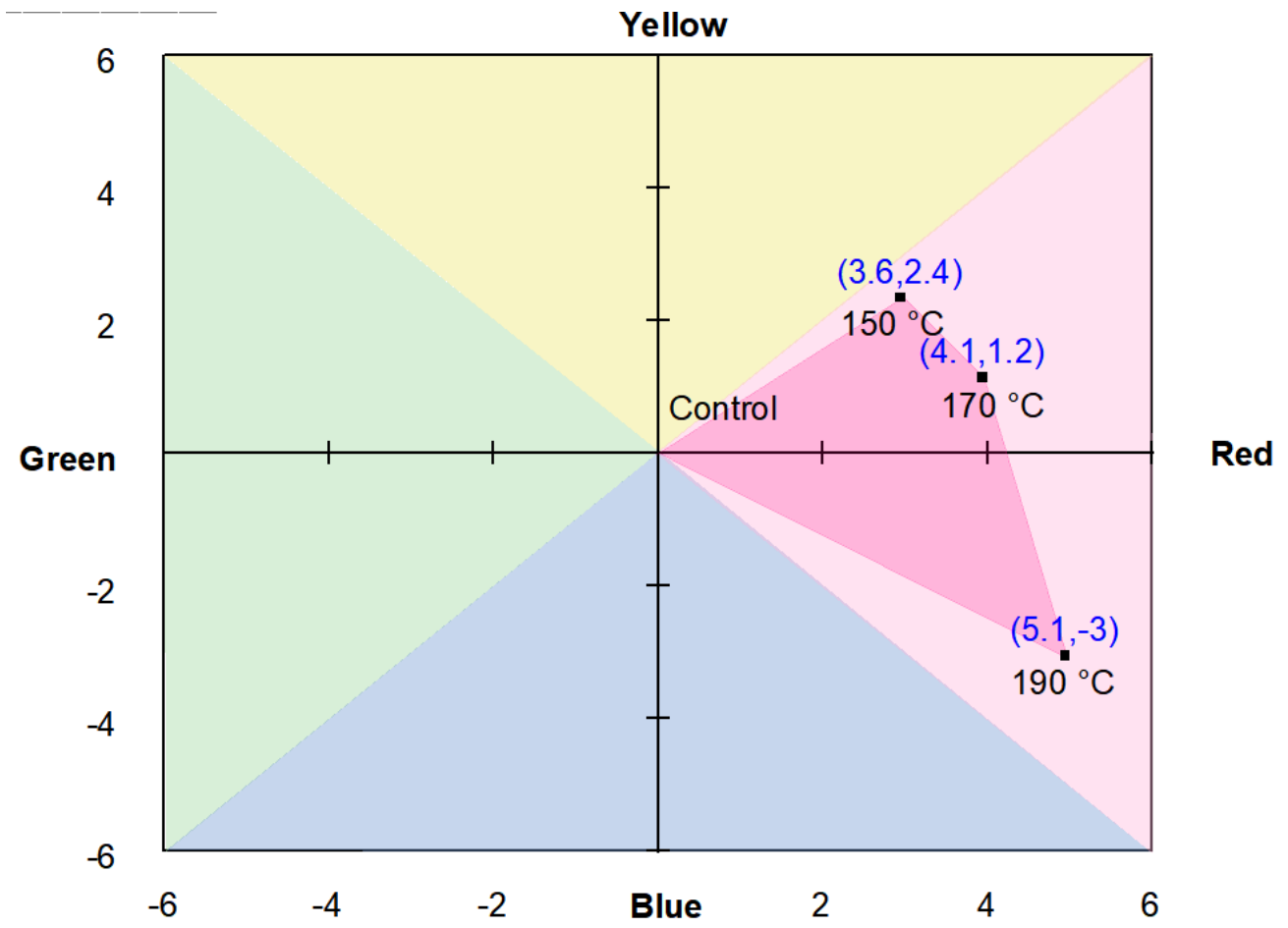

Figure 5. Colorimetric difference analysis of Masson pine wood as a function of temperature (The x-coordinate: $\Delta a^{*}$; the y-coordinate: $\Delta b^{*}$ ).

\subsection{Nanoindentation (NI)}

Environmental factors, such as temperature or humidity, will exert pressure on the coating, affecting its elastic modulus and hardness [47,48]. Figure 6 demonstrates the effect of thermal modification on the mechanical properties of the coating layer on the surface of the wood. The reduced elastic modulus $\left(E_{\mathrm{r}}\right)$ and hardness $(H)$ of the coating applied to TMWs were lower than those of 
untreated ones. When the temperature of thermal modification was $190{ }^{\circ} \mathrm{C}$, the $E_{\mathrm{r}}$ and $H$ of the coating were $1.96 \mathrm{GPa}$ and $0.07 \mathrm{GPa}$, which decreased by $12.1 \%$ and $22.2 \%$, respectively, compared with the untreated wood. The $E_{\mathrm{r}}$ and $H$ of the coating decreased with the increase in the temperature of thermal modification. From $150{ }^{\circ} \mathrm{C}$ to $190{ }^{\circ} \mathrm{C}$, the $E_{\mathrm{r}}$ and $H$ of the coating decreased by $7.1 \%$ and $12.5 \%$, respectively. This indicated that thermal modification of wood had a negative effect on the mechanical properties of the coating applied to TMWs and became worse with the increase in temperature of thermal modification. This was because wood extraction had a positive effect on the coating while the thermal modification reduced the content of wood extraction $[49,50]$. The components of the lower molecular weight of the coating embedded the CWs of TMWs after being coated, and the resin interacted with the extractions in the cell wall ultimately leading to the difference in mechanical properties.

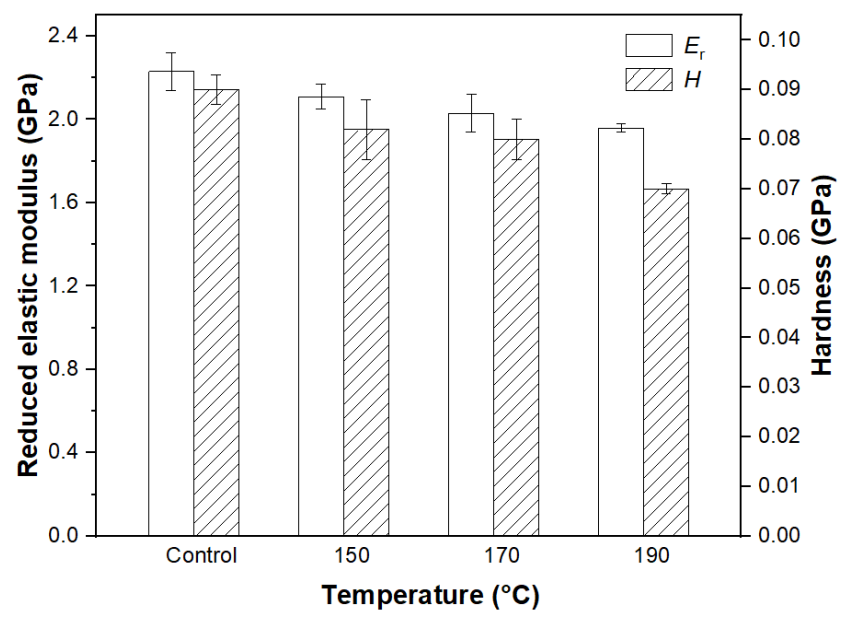

Figure 6. Effects of thermal modification on the $E_{\mathrm{r}}$ and $H$ of the coating.

As shown in Figure 7, the $E_{\mathrm{r}}$ and $H$ of the untreated wood were $15.8 \mathrm{GPa}$ and $0.34 \mathrm{GPa}$, respectively. With the increase in the temperature of thermal modification, the $E_{\mathrm{r}}$ and $H$ of the cell wall were enhanced, which increased from $15.8 \mathrm{GPa}$ to $18 \mathrm{GPa}$ and the hardness increased from $0.38 \mathrm{GPa}$ to $0.4 \mathrm{GPa}$, respectively. After thermal modification of $190{ }^{\circ} \mathrm{C}$, the $E_{\mathrm{r}}$ and $H$ increased by $14.0 \%$ and $17.6 \%$ compared with the control. In the process of thermal modification, the lignin condensation via cross-linking reactions with furfural set free from hemicelluloses, which may have contributed to the increase in the cellulose crystallinity index of the wood [51]. In addition, it is possible that the cross-linking reaction between CWs and the molecules of the coating also played an important role in improving the $E_{\mathrm{r}}$ and $H$ of CWs $[49,50]$.

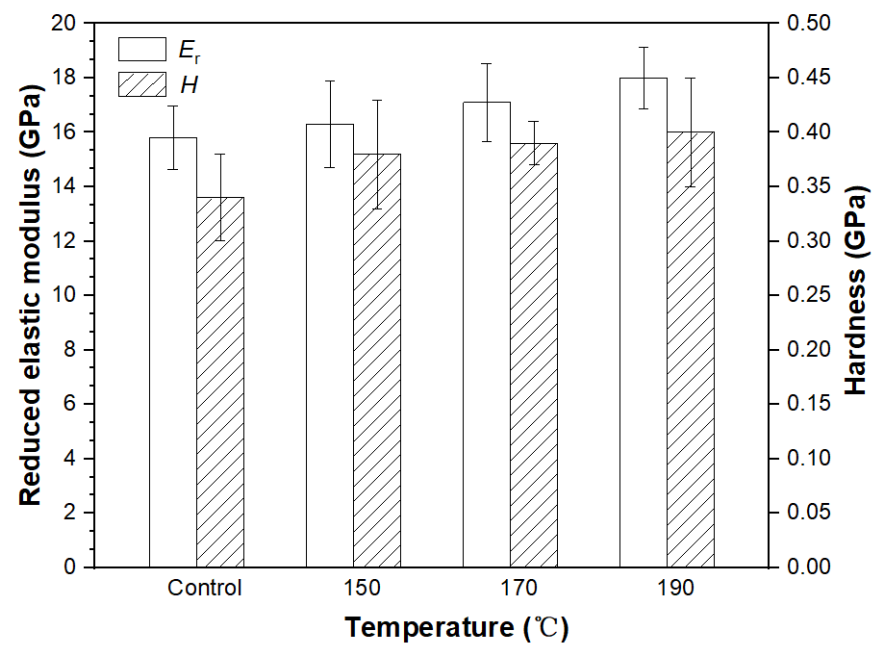

Figure 7. Effects of thermal modification on the $E_{\mathrm{r}}$ and $H$ of the cell wall. 
Figure 8 illustrates the $E_{\mathrm{r}}$ of the coating and cell walls at different locations of the natural wood and on the cross-sections of TMW samples. It was obvious that the $E_{\mathrm{r}}$ of the coating was much smaller than that of the cell wall in both the natural wood and the TMW samples. The $E_{\mathrm{r}}$ of the coating layer on the natural wood and the surfaces of TMWs were both lower than those in CWs type I (I-W) and CWs type II (II-W). The $E_{\mathrm{r}}$ of the coating of TMW In-I (I-C) decreased the most compared with natural wood, which dropped from $2.57 \mathrm{GPa}$ to $2.03 \mathrm{GPa}$. The $E_{\mathrm{r}}$ of CWs on type I (I-C) and type II (II-C) were both lower than that on type III (III-C). The $E_{\mathrm{r}}$ of TMW On-III (III-C) decreased the most when compared with the natural one, dropping from 19.06 GPa to $17.03 \mathrm{GPa}$. This was because the dispersant (ethylene glycol ethers) in the coating penetrated the cell wall [52-54]. This made the hydrogen bonds between the microfilaments break more easily, resulting in the reduction of mechanical properties of the TMWs. Similarly, the extractions in CWs have a promoting effect on the binding strength of the wood and the coating. With the rise in the temperature of heat treatment, the extractions experienced a decrease, and the connection between wood cell walls and resin weakened, leading to the decline in mechanical properties.

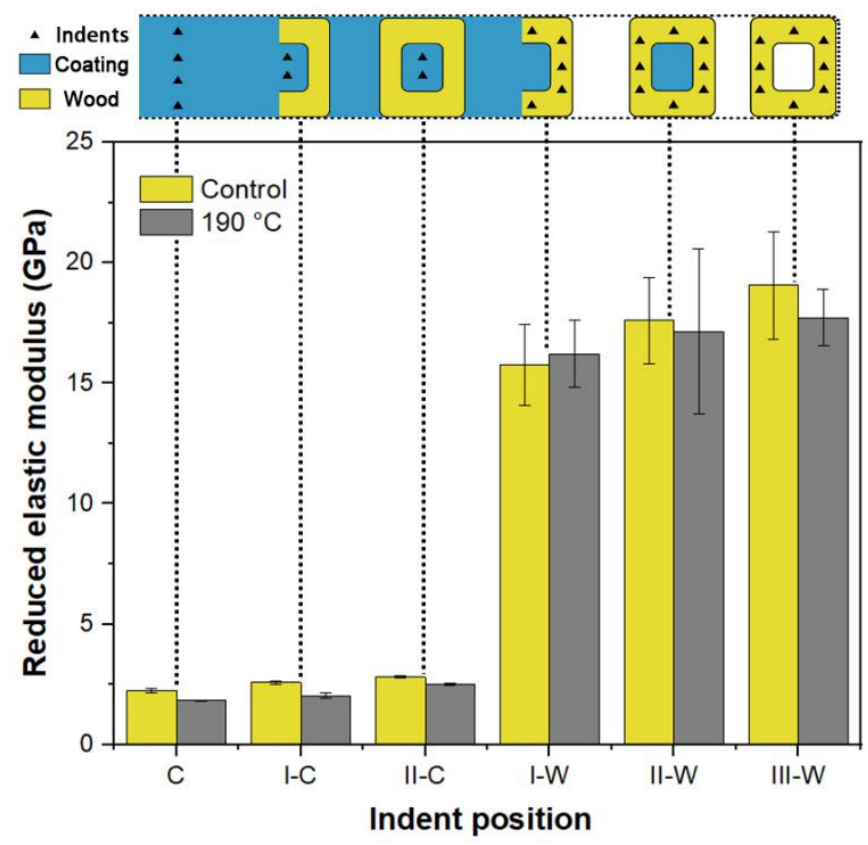

Figure 8. $E_{\mathrm{r}}$ of the coating and cell walls at different locations at the sample cross-section.

As shown in Figure 9, the $H$ of the coating was significantly lower than that of the CWs in both natural wood and TMWs. The resin used in the waterborne polyacrylic lacquer was synthesized with water as the carrier, and the coating contained a large number of hydrophilic groups, so it also had the defects of poor resistance to water and low hardness [55,56]. After thermal modification, the $H$ of the coating decreased, while the $H$ of the CWs increased. This was due to the different evaporation rates of dispersants during the curing process of coating. The evaporation rate of the coating surface was greater than that of the interior. As a result, along with the thickness of the coating, the coating that was closer to the wood had a higher hardness. On the contrary, the CWs on type III (III-C) possessed higher hardness, reaching $0.43 \mathrm{GPa}$, which was the effect of the weakened flexible connection of the CWs. 


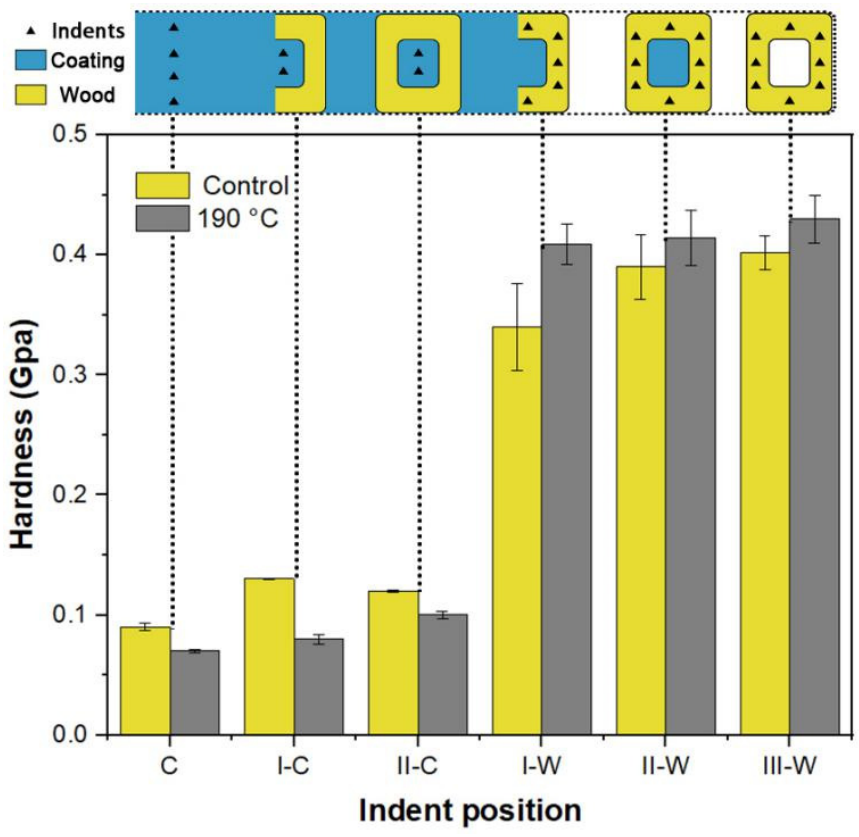

Figure 9. The hardness of the coating and cell walls at different locations at the sample cross-section.

\section{Conclusions}

The mechanical properties of the wood after thermal modification and finishing were studied by nanoindentation, which is beneficial to improve the wood treatment technology and the properties of thermal modification wood. It was found that with the increase in the temperature of thermal modification, the content of cellulose and hemicelluloses in the wood's cell walls decreased by $7.1 \%$ and $27.7 \%$, respectively, and the content of lignin increased by $3.9 \%$. The color of wood became darker and the contact angle of water on the wood surface increased. Thermal modification with temperatures ranging from 150 to $190^{\circ} \mathrm{C}$ has the potential to increase the hardness of CWs. The $E_{\mathrm{r}}$ and $H$ of the CWs with the penetration of WPA were lower than those of intact cell walls, which were far away from the coating layer, indicating that the embedding of WPA harmed the mechanical properties of wood.

Author Contributions: Conceptualization, Y.W. and F.Y.; writing-original draft preparation, X.W., J.Z. and Y.W.; investigation, H.Z. and X.W.; methodology, X.F., F.Y. and Y.W.; funding acquisition, F.Y., J.Z. and Y.W. All authors have read and agreed to the published version of the manuscript.

Funding: This research received no external funding.

Acknowledgments: The authors gratefully acknowledge the financial support for the project funded by the Special Scientific Research Fund of Construction of High-Level Teachers Project of Beijing Institute of Fashion Technology (BIFTQG201805), the Science and Technology Plan of Beijing Municipal Education Commission (KM202010012001), the “Nan Taihu Lake Elite Plan" project ((2018) No.2, Huzhou, Zhejiang Province), and the International Cooperation Joint Laboratory for Production, Education, Research, and Application of Ecological Health Care on Home Furnishing.

Conflicts of Interest: The authors declare no conflict of interest.

\section{References}

1. Kluge, M.; Veigel, S.; Pinkl, S.; Henniges, U.; Zollfrank, C.; Rössler, A.; Gindl-Altmutter, W. Nanocellulosic fillers for waterborne wood coatings: Reinforcement effect on free-standing coating films. Wood Sci. Technol. 2017, 51, 601-613.

2. Ferreira, J.; Esteves, B.; Nunes, L.; Domingos, I. Life Cycle Assessment as a tool to promote sustainable Thermowood boards: A Portuguese case study. Int. Wood Prod. J. 2016, 7, 124-129.

3. Younsi, R.; Kocaefe, D.; Poncsak, S.; Kocaefe, Y. Computational and experimental analysis of high temperature thermal treatment of wood based on ThermoWood technology. Int. Commun. Heat Mass Transf. 2010, $37,21-28$. 
4. Fang, L.; Xiong, X.; Wang, X.; Chen, H.; Mo, X. Effects of surface modification methods on mechanical and interfacial properties of high-density polyethylene-bonded wood veneer composites. J. Wood Sci. 2017, 63, 65-73.

5. Liu, X.; Wu, Z.; Zhang, J. The Effects of Heating Treatment on the Tensile Properties of Palm Petioles Fiber. Bioresources 2017, 12, 1335-1343.

6. Yang, R.; Liang, Y.; Hong, S.; Zuo, S.; Wu, Y.; Shi, J.; Cai, L.; Li, J.; Mao, H.; Ge, S.; et al. Novel Low-Temperature Chemical Vapor Deposition of Hydrothermal Delignified Wood for Hydrophobic Property. Polymers 2020, 12, 1757. [CrossRef]

7. Xia, C.; Lam, S.S.; Sonne, C. Ban unsustainable mink production. Science 2020, 370, 539.

8. Gao, L.; Lu, Y.; Zhan, X.; Li, J.; Sun, Q. A robust, anti-acid, and high-temperature-humidity-resistant superhydrophobic surface of wood based on a modified TiO2 film by fluoroalkyl silane. Surf. Coat. Technol. 2015, 262, 33-39.

9. Hosseinaei, O.; Wang, S.; Enayati, A.A.; Rials, T.G. Effects of hemicellulose extraction on properties of wood flour and wood-plastic composites. Compos. Part A Appl. Sci. Manuf. 2012, 43, 686-694.

10. Yang, R.; Cao, Q.; Liang, Y.; Hong, S.; Xia, C.; Wu, Y.; Li, J.; Cai, L.; Sonne, C.; Van Le, Q.; et al. High capacity oil absorbent wood prepared through eco-friendly deep eutectic solvent delignification. Chem. Eng. J. 2020, $401,126150$.

11. Zhang, J.; Qu, L.; Wang, Z.; Zhao, Z.; He, Z.; Yi, S. Simulation and validation of heat transfer during wood heat treatment process. Results Phys. 2017, 7, 3806-3812.

12. Yan, X.; Wang, L.; Qian, X. Influence of the PVC of Glass Fiber Powder on the Properties of a Thermochromic Waterborne Coating for Chinese Fir Boards. Coatings 2020, 10, 588. [CrossRef]

13. Boonstra, M.J.; Van Acker, J.; Tjeerdsma, B.F.; Kegel, E.V. Strength properties of thermally modified softwoods and its relation to polymeric structural wood constituents. Ann. Forest Sci. 2007, 64, 679-690.

14. Korkut, S.; Aytin, A. Evaluation of physical and mechanical properties of wild cherry wood heat-treated using the thermowood process. Maderas 2015, 17, 171-178.

15. Stanzl-Tschegg, S.; Beikircher, W.; Loidl, D. Comparison of mechanical properties of thermally modified wood at growth ring and cell wall level by means of instrumented indentation tests. Holzforschung 2009, $63,443-448$.

16. Wang, X.; Chen, X.; Xie, X.; Wu, Y.; Zhao, L.; Li, Y.; Wang, S. Effects of thermal modification on the physical, chemical and micromechanical properties of Masson pine wood (Pinus massoniana Lamb.). Holzforschung 2018, 72, 1063-1070.

17. Gindl, W.; Gupta, H.S. Cell-wall hardness and Young's modulus of melamine-modified spruce wood by nano-indentation. Compos. Part A 2002, 33, 1141-1145.

18. Mahrdt, E.; van Herwijnen, H.W.G.; Kantner, W.; Moser, J.; Giesswein, J.; Mitter, R.; Müller, U.; Gindl-Altmutter, W. Adhesive distribution related to mechanical performance of high density wood fibre board. Int. J. Adhes. Adhes. 2017, 78, 23-27.

19. Zhang, J.; Seeger, S. Polyester Materials with Superwetting Silicone Nanofilaments for Oil/Water Separation and Selective Oil Absorption. Adv. Funct. Mater. 2011, 21, 4699-4704.

20. Xiong, X.; Niu, Y.; Yuan, Y.; Zhang, L. Study on Dimensional Stability of Veneer Rice Straw Particleboard. Coatings 2020, 10, 558. [CrossRef]

21. Meng, Y.; Wang, S.; Cai, Z.; Young, T.M.; Du, G.; Li, Y. A novel sample preparation method to avoid influence of embedding medium during nano-indentation. Appl. Phys. A 2013, 110, 361-369.

22. Klapálek, P.; Prošek, Z.; Jíra, A.; Melzerová, L. Evaluation of micromechanical properties of carbon fiber fabric using nanoindetation. Acta Polytech. CTU Proc. 2017, 13, 66-70.

23. Jiang, Z.; Yu, Y.; Qin, D.; Wang, G.; Zhang, B.; Fu, Y. Pilot investigation of the mechanical properties of wood flooring paint films by in situ imaging nanoindentation. Holzforschung 2006, 60, 698-701.

24. Konnerth, J.; Valla, A.; Gindl, W. Nanoindentation mapping of a wood-adhesive bond. Appl. Phys. A 2007, $88,371-375$.

25. Nowak, J.D.; Rzepiejewska-Malyska, K.A.; Major, R.C.; Warren, O.L.; Michler, J. In-situ nanoindentation in the SEM. Mater. Today 2010, 12, 44-45.

26. Wu, Y.; Wu, J.; Wang, S.; Feng, X.; Chen, H.; Tang, Q.; Zhang, H. Measurement of mechanical properties of multilayer waterborne coatings on wood by nanoindentation. Holzforschung 2019, 73, 871-877. 
27. Kol, H.S. Characteristics of heat-treated Turkish pine and fir wood after ThermoWood processing. J. Environ. Biol. 2010, 31, 10071.

28. Gurleyen, L.; Ayata, U.; Esteves, B.; Gurleyen, T.; Cakiciere, N. Oak Wood Parquets. BioResources 2019, $14,1838-1849$.

29. Ayata, U.; Gurleyen, L.; Esteves, B.; Gurleyen, T.; Cakıcıer, N. Effect of Heat Treatment (ThermoWood) on Some Surface Properties of Parquet Beech (Fagus orientalis Lipsky.) with Different Layers of UV System Applied. BioResources 2017, 12, 3876-3889.

30. Yan, Y.; Herzele, S.; Mahendran, A.; Edler, M.; Griesser, T.; Saake, B.; Li, J.; Gindl-Altmutter, W. Microfibrillated Lignocellulose Enables the Suspension-Polymerisation of Unsaturated Polyester Resin for Novel Composite Applications. Polymers 2016, 8, 255. [CrossRef]

31. Esteves, B.; Domingos, I.; Pereira, H. Heat Treatment of Pine Wood. Bioresources 2008, 3, 142-154.

32. Xu, D.; Ding, T.; Li, Y.; Zhang, Y.; Zhou, D.; Wang, S. Transition characteristics of a carbonized wood cell wall investigated by scanning thermal microscopy (SThM). Wood Sci. Technol. 2017, 51, 831-843.

33. Poncsak, S.; Kocaefe, D.; Younsi, R. Improvement of the heat treatment of Jack pine (Pinus banksiana) using ThermoWood technology. Eur. J. Wood Wood Prod. 2011, 69, 281-286.

34. Barletta, M.; Bellisario, D. Manufacture and characterization of free-standing epoxy-polyester films. Prog. Org. Coat. 2011, 70, 259-272.

35. Oliver, W.C.; Pharr, G.M. An improved technique for determining hardness and elastic modulus using load and displacement sensing indentation experiments. J. Mater. Res. 1992, 7, 1564-1583.

36. Pharr, G.M.; Oliver, W.C. Measurement of Thin Film Mechanical Properties Using Nanoindentation. Mrs Bull. 1992, 17, 28-33.

37. Jakes, J.E.; Frihart, C.R.; Beecher, J.F.; Moon, R.J.; Stone, D.S. Experimental method to account for structural compliance in nanoindentation measurements. J. Mater. Res. 2008, 23, 1113-1127.

38. Jakes, J.E.; Frihart, C.R.; Beecher, J.F.; Moon, R.J.; Resto, P.J.; Melgarejo, Z.H.; Suárez, O.M.; Baumgart, H.; Elmustafa, A.A.; Stone, D.S. Nanoindentation near the edge. J. Mater. Res. 2009, 24, 1016-1031.

39. Boonstra, M.J.; Tjeerdsma, B. Chemical analysis of heat treated softwoods. Holz Als Roh- Und Werkst. 2006, 64, 204-211.

40. Liu, M.; Qing, Y.; Wu, Y.; Liang, J.; Luo, S. Facile fabrication of superhydrophobic surfaces on wood substrates via a one-step hydrothermal process. Appl. Surf. Sci. 2015, 330, 332-338.

41. Tu, K.; Wang, X.; Kong, L.; Guan, H. Facile preparation of mechanically durable, self-healing and multifunctional superhydrophobic surfaces on solid wood. Mater. Des. 2018, 140, 30-36.

42. Jämsä, S.; Ahola, P.; Viitaniemi, P. Long-term natural weathering of coated ThermoWood. Pigment Resin Technol. 2000, 29, 68-74.

43. Liu, C.; Wang, S.; Shi, J.; Wang, C. Fabrication of superhydrophobic wood surfaces via a solution-immersion process. Appl. Surf. Sci. 2011, 258, 761-765.

44. Yang, S.; Wang, L.; Wang, C.; Chen, L.; Chen, S. Superhydrophobic Thermoplastic Polyurethane Films with Transparent/Fluorescent Performance. Langmuir 2010, 26, 18454-18458. [PubMed]

45. Zhao, H.; Law, K.; Sambhy, V. Fabrication, Surface Properties, and Origin of Superoleophobicity for a Model Textured Surface. Langmuir 2011, 27, 5927-5935.

46. Tadanaga, K.; Morinaga, J.; Minami, T. Formation of Superhydrophobic-Superhydrophilic Pattern on Flowerlike Alumina Thin Film by the Sol-Gel Method. J. Sol-Gel Sci. Technol. 2000, 19, 211-214.

47. Liang, K.; Du, G.B.; Hosseinaei, O.; Wang, S.Q.; Wang, H. Mechanical Properties of Secondary Wall and Compound Corner Middle Lamella near the Phenol-Formaldehyde (PF) Adhesive Bond Line Measured by Nanoindentation. Adv. Mater. Res. 2011, 236-238, 1746-1751.

48. Chen, C.K.; Feng, H.M.; Lin, H.C.; Hon, M.H. The effect of heat treatment on the microstructure of electroless Ni-P coatings containing SiC particles. Thin Solid Film 2002, 416, 31-37.

49. Wu, Y.; Sun, Y.; Yang, F.; Zhang, H.; Wang, Y. The Implication of Benzene-Ethanol Extractive on Mechanical Properties of Waterborne Coating and Wood Cell Wall by Nanoindentation. Coatings 2019, 9, 449. [CrossRef]

50. Yang, L.; Liu, H. Effect of a Combination of Moderate-Temperature Heat Treatment and Subsequent Wax Impregnation on Wood Hygroscopicity, Dimensional Stability, and Mechanical Properties. Forests 2020, 11, 920. [CrossRef]

51. Wang, X.; Li, Y.; Wang, S.; Yu, W.; Deng, Y. Temperature-dependent mechanical properties of wood-adhesive bondline evaluated by nanoindentation. J. Adhes. 2017, 93, 640-656. 
52. Liu, C.; Zhang, Y.; Wang, S.; Meng, Y.; Hosseinaei, O. Micromechanical Properties of the Interphase in Cellulose Nanofiber-reinforced Phenol Formaldehyde Bondlines. BioResources 2014, 9, 5529-5541.

53. Gindl, W.; Zargar-Yaghubi, F.; Wimmer, R. Impregnation of softwood cell walls with melamine-formaldehyde resin. Bioresour. Technol. 2003, 87, 325-330. [PubMed]

54. Van den Bulcke, J.; Rijckaert, V.; Van Acker, J.; Stevens, M. Quantitative measurement of the penetration of water-borne coatings in wood with confocal lasermicroscopy and image analysis. Holz Als Roh- Und Werkst. 2003, 61, 304-310.

55. Zhao, R.; Chen, Y.; Liu, G.; Jiang, Y.; Chen, K. Fabrication of self-healing waterbased superhydrophobic coatings from POSS modified silica nanoparticles. Mater. Lett. 2018, 229, 281-285.

56. Wang, S.; Hu, Z.; Shi, J.; Chen, G.; Zhang, Q.; Weng, Z.; Wu, K.; Lu, M. Green synthesis of graphene with the assistance of modified lignin and its application in anticorrosive waterborne epoxy coatings. Appl. Surf. Sci. 2019, 484, 759-770.

Publisher's Note: MDPI stays neutral with regard to jurisdictional claims in published maps and institutional affiliations.

(C) 2020 by the authors. Licensee MDPI, Basel, Switzerland. This article is an open access article distributed under the terms and conditions of the Creative Commons Attribution (CC BY) license (http://creativecommons.org/licenses/by/4.0/). 